\title{
EVOLUCIÓN DEL PÓSITO ALICANTINO DURANTE EL REINADO DE CARLOS III (1759-1788). (LOS CONFLICTOS GENERADOS EN TORNO AL PAN)
}

\author{
Ma Teresa AGÜERO DÍEZ
}

\begin{abstract}
Resumen
Con la creación en 1752 del pósito en Alicante se pretendió garantizar el abastecimiento triguero de la población. Sin embargo, la proximidad al mar y las altas temperaturas en los meses estivales hacía muy difícil la conservación del grano almacenado lo que, unido a una pésima gestión, motivó la pronta decadencia del pósito y su ineficacia para responder a las necesidades de la ciudad.
\end{abstract}

\begin{abstract}
With the creation in 1752 of the granary in Alicante was intended to guarantee the supply of grain for the population. However, the proximity to the sea and the high temperatures in the summer months made the conservation of the stored grain very difficult, which in combination with a wretched management, motivated the fast decadence of the granary and its inefficiency for meeting the needs of the city.
\end{abstract}

Mediante decreto de 16 de marzo de 1751 el secretario de Estado y del despacho universal de Gracia y Justicia, pasaba a controlar todos los pósitos de España como Superintendente general de Pósitos. Cuarenta años más tarde, en 1792 el conde de Aranda devolvía al Consejo sus prerrogativas respecto a estos organismos cuya polémica evolución fué sucesiva y a veces simultáneamente ensalzada o denostada según el punto de vista asumido o las circunstancias concretas que en cada momento interesara destacar. El reinado de Carlos III, inmerso de lleno entre estos dos hitos que marcan un claro intento de orientar un capítulo tan decisivo para la vida cotidiana como lo era el suministro del grano, representa un período útil para comprender la evolución de los pósitos instalados en territorio español durante el siglo XVIII.

La oportunidad de analizar el funcionamiento del cabildo alicantino durante las tres décadas correspondientes al reinado carlotercerista, nos ha permitido realizar un análisis de la evolución del pósito municipal, en la cual distinguimos tres etapas: la primera llegaría hasta la barrera de los dos años correlativos de 1765-66, en los que 
acontecen la Pragmática de Liberación de comercio de granos, del 11 de julio de 1765 y posteriormente, la reforma municipal instaurada en el Auto Acordado de 5 de mayo de 1766, jalonados ambos hechos por la sacudida de los motines de marzo; en la segunda (1766-1775), podremos tener ocasión de plantear ampliamente la repercusión que en nuestro municipio tuvo la intervención de Diputados y Personeros del común, y la tercera (1775-1789), se nos presenta inmersa en una coyuntura al alza violenta de precios junto a la intervención española en el conflicto de la guerra americana (1776), a partir del año 1779. Durante este período la incidencia del pósito dentro de la política de abastecimiento del municipio está ya en franca regresión.

Independientemente de esta división en el tiempo, es preciso destacar que la producción triguera local alicantina, en el mejor de los casos, sólo cubría el consumo de los tres o cuatro meses posteriores a la cosecha, es decir se partía de una situación de subproducción que tenía que ser paliada por la importación de grano procedente de La Mancha o, en la mayoría de los casos, de tipo ultramarino, sobre todo del enorme granero que suponía la península italiana. ${ }^{1}$

\section{ANTECEDENTES DEL PÓSITO}

El pósito alicantino se creó en 1752, aunque ya existían precedentes de este sistema desde mediados del s. XVI, al crearse un mecanismo municipal para asegurar al pueblo el abastecimiento de cereal panificable; esta forma de aprovisionamiento sufrió diversos avatares hasta desembocar en el nuevo pósito.

Las nuevas ordenanzas fueron proyectadas por el corregidor marqués de Alós, y constan de 21 artículos que bajo el título de «Ordenanzas para el buen régimen, administración y consistencia del pósito de granos establecido en la ciudad de Alicante», señalaban los objetivos, dirección, administración, naturaleza de su reserva monetaria y por último el sistema regulador de las compras y ventas de grano por él efectuadas. La finalidad del pósito alicantino era únicamente la de asegurar el grano o harina para el panadeo, cuando estos productos escaseaban. ${ }^{2}$

El Superintendente dictaba los menores detalles para la administración del pósito, por ejemplo, el tipo de sello que debía de colocarse en todos los documentos de entrada o salida de granos, que debían de ser de sello cuarto. ${ }^{3}$

La cantidad con la que el pósito inició su nueva andadura en 1752 era de 4.000 libras procedentes del arca de propios de la ciudad; esta cantidad se depositó para su control en un arca de tres llaves: una quedaba en poder del corregidor, otra en manos de un regidor electo por el concejo y, la tercera, se entregaba al administrador. Para garantizar la continuidad de esta fianza se exigía su dependencia exclusiva de la Superintendencia general de pósitos y del Consejo de Castilla, permaneciendo al margen de cualquier cargo, indemnización u obligación dependiente de la ciudad.

1. En agosto de 1764, el diputado Alcaraz informa que «tiene noticias de falta de granos en Italia». En vista de lo cual se le encomienda proveer al pósito de trigo procedente de las zonas colindantes, al precio de 9 libras y media el cahíz. A.M.A. Cabildos. Arm 9, lib 54, acta capitular 7-8-64.

2. Enrique GIMÉNEZ LÓPEZ. Alicante en el s. XVIII, Economía de una ciudad portuaria en el Antiguo Régimen, Valencia 1981, p. 297.

3. A.M.A. Cabildos Ar. 9, Lib. 54, acta capitular de 9 de octubre de 1764. 
Todo el proceso de compra de grano estaba regulado minuciosamente en los diferentes artículos, siendo el paso previo extraer del arca del pósito la cantidad necesaria para la operación y, para ello, se necesitaba reunir a los regidores en sesión capitular, fijando la cantidad de grano y la persona comisionada al efecto con el fin de hacerla depositaria de la libranza. Era deber del comisionado, presentar en cabildo la justificación de los precios de compra, una vez adquirido el trigo garbillado y colado (arts. 6,7 y 8).+*

El Ayuntamiento era el administrador del pósito y, en virtud del art. 9, tenía facultad para nombrar una persona sobre la que delegaba estas funciones; esta persona no debía ostentar cargo concejil alguno (art. 12) y era su obligación llevar la contabilidad y presentar las cuentas al concejo para esperar su aprobación, entre el 15 y el 24 de junio de cada año (arts. 5, 10 y 20). ${ }^{5}$ A partir de diciembre del año 1773, y por orden del Superintendente D. Manuel de Roda, las cuentas del pósito pasaron a considerarse desde el 1 de enero hasta el 31 de diciembre. ${ }^{6}$

La figura del administrador del pósito era muy propicia a generar conflictos a su alrededor, dada la responsabilidad de su cargo y a la vez la picaresca que generaba el tratamiento del tema. Las numerosas irregularidades que se detectaron a lo largo de la gestión ejercida por el administrador alicantino Vicente Ghessy, no impidieron, sin embargo su larga estancia en esta ocupación que abarca casi todo nuestro período de estudio, hasta que el 14 de marzo de 1784 fue nombrado Juan Sese Boria, como nuevo administrador?

El Arca de los fondos del pósito se custodiaba en la residencia del corregidor y siempre que había una variación en ello, el cabildo se hacía eco, como ocurrió en marzo de 1760 cuando se planteó por parte de Juan Rovira, diputado del pósito, la necesidad de contar los fondos que habían tenido que ser trasladados a la casa del Alcalde Mayor, a propósito de un viaje que el corregidor se había visto en la necesidad de efectuar. La preocupación de Rovira era que: «Aún no se habían contado los caudales que hay, ni si están integros 6.263 libras, 14 sueldos, 5 dineros». El acuerdo que se tomó en consecuencia fue «notificar a Vicente Ghessy, a fin de que el día siguiente acuda con Rovira para contarlo».8

\section{EVOLUCIÓN DEL PÓSITO ALICANTINO (1759-1765)}

El inicio de reinado de Carlos III coincide aún con un período de marcado signo negativo (plagas en los años 1758, 1759, continuación del bloqueo de llegadas de grano, por causa de la guerra franco-inglesa, etc). No obstante, se auspiciaba ya una

4. Ibid.

* En Alicante este requisito no se observó salvo en raras ocasiones hasta que en 1778 se volvió a insistir sobre su conveniencia.

5. Ibid

6. A.M.A. Cabildos, Arm 9, Lib 68, f.443.

7. En enero de 1762 , cuando el administrador Vicente Ghessy tuvo que añadir 8.000 libras a su fianza, se negó alegando insolvencia. Tampoco su fiador, Gabriel Puigcerver presentó los títulos que acreditaban su fianza, situación que forzó el cese de Ghessy. Finalmente la intervención del Superintendente logró su reincorporación. A.M.A. Cabildos. Arm 9, lib, 52, actas capitulares de 25 de enero, 5 de febrero y 6 de marzo de 1762 .

8. A.M.A. Cabildos. Arm 9, lib 50, acta capitular de 29 de marzo de 1760. 
nueva etapa, y a partir de 1762 , se aprecia un despegue, en el que, sin embargo, se va revelando en Alicante, como en otras muchas ciudades, la insuficiencia del pósito como medio a través del cual el común se vería protegido de la escasez de grano o de los precios excesivos. La obligación del cabildo, administrador último de los fondos, de no perder dinero, obligaba muchas veces a vender el trigo del pósito a un precio elevado aún mezclando éste con otro adquirido en inmejorables condiciones, ya que el precio final de esta mezcla siempre era superior al que los harineros y el común apreciaban en el mercado público. En estos primeros años, el principal conflicto que el cabildo tuvo que encarar fue la protesta de los harineros que reiteradamente afirmaban no obtener un beneficio aceptable en la venta de harina.

En otoño de 1760 se apreciaba una incipiente escasez de granos por lo cual hubo que comprar en Relleu 200 cahíces. A pesar de ser ésta una etapa de sequía, no había razón en Alicante para que el trigo y la harina se encarecieran, existiendo un contraste evidente entre el precio a que se vendía el trigo fuera del pósito y los precios a los que el Ayuntamiento obligaba comprar el grano.

Desde el 27 de octubre de 1760 hasta el 6 de junio de 1761 se compraron 511 cahíces de trigo para el pósito, pero ya desde el mes de mayo se había comenzado a dar salida al trigo acopiado, prohibiéndose la introducción de trigo forastero hasta que se despachara el del pósito.

Las reiteradas crisis sufridas durante los meses primaverales -o mayores- se intentaron paliar durante el año 1762, combinando la compra de trigo tanto de los pueblos aledaños, como de los granos procedentes del comercio marítimo. En mayo de este año de 1762 el cabildo no dudó en recurrir a la requisa para poder acopiar trigo a buen precio cuando llegó a nuestra bahía una polacra liornesa, de nombre Ntra. Sra del Carmen y S. Miguel Arcángel, con una carga de trigo propiedad del comerciante D.Bernardo Viale, oriundo de la ciudad de Calleri (Cerdeña). ${ }^{9}$ Al parecer, el capitán de la liornesa, tenía la misión de transportar ese trigo a Cartagena o Málaga, pero al hacer escala en nuestra ciudad, su barco fue retenido en la bahía por el corregidor, quien, tras notificar el hecho al Capitán General del reino, nombró dos diputados para efectuar la compra, imponiendo el precio de 7 libras el cahíz y advirtiendo al capitán que si esto no le convenía debía desembarcar, almacenar su trigo y no intentar venderlo antes de que la ciudad hubiera despachado el que tenía en el pósito. Ante esta medida de fuer$\mathrm{za}$, el propietario del trigo intervino mediante una carta al cabildo y otra al Intendente General del pósito, que abogó por que se concediera a Viale la venta del trigo al mejor precio «...con apercibimiento de resarcirle los daños y perjuicios por quien intentase lo contrario. Y si le conviniese pasar el trigo a Valencia o a Cartagena -aquí vemos que el Intendente abre la posibilidad de un nuevo destino para el trigo-, se le permitirá recibiendo antes las fianzas que ofrece». ${ }^{10}$

Finalmente, el propietario del cargo accedió a vender el trigo en la propia ciudad al precio de 7 libras, aún reconociendo que perdía en la operación más de 1.200 pesos. La cantidad exacta que se adquirió para el pósito fue de 900 cahíces, pero al existir ya en el mismo 400 cahíces y siendo el precio de venta que se había fijado para

9. Según el memorial de Viale, el capitán fue detenido bajo pretexto de manifestar su intención de viajar hasta Lisboa... plaza sospechosa en el día. A.M.A. Cabildos. Arm 9, Lib 52, Acta capitular de 14 de mayo de 1762 .

10. A.M.A. Cabildos. Arm. 9, lib 52. Acta capitular de 14 de mayo de 1762. 
ellos de 10 libras, 3 sueldos y 6 dineros cada cahíz, se acordó que «un trigo con otro, se vendiera a 8 libras y 10 sueldos el cahíz» mediante lo cual se conseguía algún beneficio para el pósito y no se gravaba al común, añadiéndose que «los harineros no pueden vender la arroba de harina a más de 14 sueldos y que la libra de harina se venda a 6 dineros»."

La respuesta de los harineros no se hizo esperar y sus argumentos eran que no podían dar la arroba de harina a 14 sueldos comprando el cahíz de trigo a 8 libras y 2 sueldos porque no se sacaban el jornal. El acuerdo en consecuencia fue que se vendiera cada cahíz a 8 libras y 5 sueldos, y la arroba de harina a 14 sueldos y dos dineros con lo que quedaba de ganancia a los harineros, 8 sueldos en menudos por cahíz. Enterados los harineros de esta resolución comunicaron al consistorio que: «...no se conforman enteramente con ella ni se obligan a abastecer la plaza, pareciéndoles corta recompensa, por lo que deseando proveer en bien de su común resuelven que se haga una porción de harina para abastecer la plaza y que se tenga de repuesto» ${ }^{12}$. Se recurrió, por tanto, a un sistema de servicios mínimos por parte de los harineros sin avenirse a los intereses que el consistorio indicaba.

A lo largo del año 1763, el funcionamiento del pósito tampoco dio los resultados que cabía esperar y, en abril, los harineros se quejaban ante el consistorio de que tras haber comprado trigo a precio excesivo, un bando dado por la Asegurada, les obligaba a rebajar el precio de la harina, perdiendo mucho dinero. Por otra parte denunciaban que en el pósito no siempre se les vendía el trigo que necesitaban. Ante estas quejas, se reclamó a Vicente Ghessy una relación individual del precio a que se había vendido el trigo «con toda claridad y beneficio que resulta de su venta». ${ }^{13}$

Al descontento de los harineros, se unía el de una buena parte de los capitulares que no estaban de acuerdo con la decisión tomada unilateralmente entre el corregidor y el administrador, en cuanto a comprar una carga de trigo al comerciante Jerónimo Ortiza, mientras eran testigos de que en el arca del pósito no existían fondos y el producto de la venta de granos no se depositaba en ella como prevenían las ordenanzas. ${ }^{14}$ Tras una protesta general, coincidiendo unánimemente en lo perjudicial que era comprar trigo nuevo sin vender antes el existente en el pósito y no dejar constancia de las operaciones semanalmente, se consiguió al menos que el corregidor asumiera la responsabilidad de los hechos. La razón que el mencionado corregidor alegaba para haber tramitado esta compra era la inminencia del verano con la sequía y consiguiente imposibilidad de moler el trigo. ${ }^{15}$

Los rumores de escasez con que concluyó el año 1763 siguieron presidiendo el funcionamiento del pósito durante el año 1764, aunque sin datos reales que corroboraran este sentir general. A raíz del acuerdo que se tomó el 22 de febrero como medida de urgencia para dar salida al trigo del pósito, se obligó a los panaderos a com-

11. A.M.A. Cabildos, Arm 9, lib 52, Acta capitular de 10 de mayo de 1762.

12. A.M.A. Cabildos, Ibíd.

13. A.M.A. Cabildos, Arm 9, lib 53. Acta capitular de 11 de abril de 1763.

14. Se habían vendido 1932 cahíces de trigo del pósito, de los que no había ninguna constancia en cuanto a su producto. A.M.A. Cabildos. Arm 9, Lib 53, Acta capitular de 18 de abril de 1763.

15. El diputado Pobil se encargó de rebatir esta decisión porque según él... "el día que empezó a venderse el trigo que $S$. Ex. compró de Jerónino Ortiza, lo vendían los comerciante en el muelle a menor precio». A.M.A. Cabildos. Arm 9, lib 53. Acta capitular de 18-4-1763. 
prar $1 / 2$ cahíz de trigo diario ${ }^{16}$ sin concretar de momento el precio, que se deduciría del coste del trigo y salarios anuales. Ante esta postura de fuerza los panaderos reaccionaron negándose a comprar trigo o, en caso contrario, pedían que se les fiara, a lo que el consistorio respondió: «...Que se les obligue a tomar a cada uno el medio cahíz diario acordado y no cumpliéndolo se les cierren los hornos y tomen las demás providencias conducentes». ${ }^{17}$

Poco después se constató que existía una acumulación de granos en el pósito y que realmente se estaba almacenando a riesgo de que se maleara. En mayo, el diputado para el pósito, Jose Alcaraz, recibió facultades para vender el trigo almacenado, con libertad para fijar su precio.

La premura se debía a la necesidad de dar salida al grano porque amenazaba corrupción. ${ }^{18}$ Hacía escasamente dos meses los panaderos se veían en aprietos para poder conseguir un margen de beneficio a su actividad, mientras que llegado el momento de hacer acopio era preferible vender a cualquier precio porque de lo contrario habría que deshacerse de una buena porción de grano sin utilidad alguna.

Durante todo el año 1765 se percibió en las reuniones capitulares la preocupación por evitar que se llegara a una situación de escasez en la ciudad, ante las noticias inquietantes que se recibían de otras plazas marítimas. No hay que olvidar tampoco, la profunda crisis de subprodución que se sufría en Castilla, consecuencia de una pertinaz sequía, que forzó al Gobierno a una masiva importación de grano por vía marítima.

La escalada agresiva de los precios debió inducir al marqués de Esquilache en su calidad de Secretario de Hacienda, a tomar las medidas pertinentes con las casas comerciales y mercados especializados en el surtimiento de granos: Londres, Marsella, Génova, Nápoles, Palermo, en orden a la conducción de cereal con destino al interior peninsular. Alicante destacó como primer punto de recepción, en cuanto a volumen de grano recibido en el litoral valenciano, muy por delante de Valencia y de cualquier otro puerto español de los que recibían trigo para la Corte ${ }^{19}$. En el mes de mayo de este mismo año 1765 quedó patente en cabildo, que la ciudad tenía un acceso pleno al trigo que se desembarcaba en nuestra bahía con destino a la Corte..$^{20}$

Esta postura quedó corroborada en junio, mediante una orden del marqués de Esquilache que se leyó en cabildo el día de 18 dicho mes preveyendo que «...del trigo ultramarino venido por disposición de S.M. se facilite a los pueblos de Valencia y Murcia el necesario para su subsistencia pagando la fanega a 35 reales de vellóns. ${ }^{21}$ Pero, a pesar de los acopios, efectuados entre los meses de octubre y noviembre, a fi-

16. Se mezclaban $2 / 3$ de trigo ultramarino y 1/3 de tierra. A.M.A. Cabildos, Arm 9, Lib 54, Acta capitular de 22 se febrero de 1764 .

17. A.M.A. Cabildos. Arm 9, lib. 54. Acta capitular de 10 de marzo de 1764.

18. A.M.A.Cabildos Arm 9, Lib 54, Acta capitular de 4 de mayo de 1764.

19. Entre octubre de 1764 y junio de 1766 desembarcaron en el puerto de Alicante 861.790 fanegas y 2 celemines de grano. Jose Miguel PALOP RAMOS, El litoral valenciano y el avituallamiento triguero de Madrid. Hambres de 1754 y 1766. Estudis, n 5, 1976, p. 137.

20. Gerónimo Ortiza, comisionado de los trigos de S.M., notificó su voluntad de facilitar ... a la ciudad y a los pueblos de su gobernación todo el grano que se necesitase (no sólo 35 cahices diarios) y todo el trigo necesario para el pósito, para convertirlo en harina. A.M.A. Cabildos. Arm 9, Lib 55, acta capitular de 10 de mayo de 1765.

21. A.M.A. Cabildos. Arm 9, lib 55. Acta capitular de 18 de junio de 1765 
nales de este mismo mes, el diputado Alcaraz ${ }^{22}$ hacía la observación de que... «está casi extinto el trigo del pósito con riesgo gravísimo de que falte el pan». ${ }^{23}$

Todas las ocasiones para poder adquirir grano en buenas condiciones fueron aprovechadas en este difícil año ${ }^{24}$, sin reparar muchas veces en los altos precios que se tenían que pagar por el trigo. La justificación que daba Alcaraz al comprar un cargo a 14 libras y 10 dineros era que «como es ventajosa por la escasez en las plazas marítimas en donde sin pararse en la exhorbitancia de los precios, aprovechan cuantas ocasiones se les proporcionan hasta vencer dificultades de la mayor gravedad, cono acaba de ocurrir en Cartagena». ${ }^{25}$

Es evidente pues, que durante esta primera etapa las bruscas alzas de precios o las inquietantes noticias de falta de granos en los lugares que podían ser puntos de aprovisionamiento, seguían siendo la tónica cotidiana en el municipio alicantino a pesar de la aplicación de las distintas medidas por parte del gobierno municipal en una línea, y del central en otra.

\section{APLICACIÓN Y REPERCUSIONES DE LA REAL PRAGMÁTICA DE 1765}

Mientras tanto, la política liberalizadora que había comenzado a fraguarse tiempo atrás se consolidaba en forma de Real Pragmática sobre abolición de tasas y autorización del libre comercio. La intervención en su promulgación por parte de Esquilache se intuye, si tenemos en cuenta la inclinación por parte del ministro italiano hacia una política de fomento de la labranza y de imitación a lo que se venía practicando ya en Inglaterra, Francia o Italia, en cuanto a la libertad de comercio. Para Campomanes el problema residía en las mismas autoridades locales encargadas del abastecimiento de los pueblos y en el hermético recinto que constituía aún el bloque formado por el cuerpo de regidores y la Iglesia; por otra parte la disminución del precio de los granos era tan perjudicial para el común como para los dueños de las tierras ya que si aquel disminuía lo hacían también los jornales, y lo mismo ocurría con todos los demás productos necesarios para el sustento de la población.

Se trataba de depurar funciones y la del Consejo era sin duda responsabilizarse de que no hubiese escasez de grano para el acopio público; si quedaba demostrado, como así era, que los pósitos no cumplían su función, era necesario sanearlos mediante una nueva reglamentación; había que sistematizar además lo que el gobierno

22. La actividad desplegada por el diputado para el pósito José Alcaraz durante este año fue muy notable, comprando en el mes de noviembre: 120 cahíces (Walter y Porte), a 13 libras y 7 sueldos cahíz, 150 cahíces a Bernardo Ferrero, a 14 libras cahíz, 464 cahíces, y 5 barchillas a 14 libras el cahíz y 1.400 fanegas de trigo blando, a 12 libras cahíz. A.M.A. Cabildos, Arm. 9, Lib. 55, Acta capitular de 26 de noviembre de 1765 .

23. A.M.A. Cabildos, Ar. 9, Lib. 55, acta capitular de 26 de noviembre de 1765.

24. El 15 de noviembre recaló en la bahía alicantina y a causa de una vía de agua, un navío con trigo procedente de Sicilia. Su Capitán sólo se ofreció para poner a la venta la cantidad de trigo que precisaba evacuar si quería poner su barco navegable. El destino de su carga era Valencia donde, según sus palabras ...ocurre el fundado recelo de escasez que en todas partes. A.M.A. Cabildos. Arm 9, Lib 55, Acta capitular de 15 de noviembre de 1765 .

25. Ibid. 
entendía por comerciantes. ${ }^{26}$ Para Gonzalo Anes la promulgación de esta Pragmática fue un triunfo de quienes en el país y en el gobierno presionaron en esa dirección. ${ }^{27}$

Para poder comprender la evolución del pósito a partir de este momento es indispensable señalar los aspectos más relevantes de la Real Pragmática y que incidían de manera más directa en las cuestiones relativas al abasto ciudadano. Se destacaba en ella la relevancia de los Diputados del Común en el abasto de trigo, debiendo asistir a todas las juntas del pósito e intervenir en todo lo concerniente al abasto de pan, actuando en todo lo concerniente a la bondad del género, legalidad del precio y sobre todo vigilantes de que tanto la Pragmática del 11 de Julio, como la Provisión acordada el 30 de octubre, se cumplieran, teniendo derecho tanto a voto como a testimonio. Otra parte que les concernía era la de velar para que los libros de cuentas estuvieran ordenados, expresando claramente las partidas de granos que se compraban y se vendían.

El carácter eminentemente público que debían de tener los pósitos, a disposición de los pueblos de la comarca en caso de necesidad, se preveía mediante la prohibición de los gremios o cofradías. En esta misma línea de evitación de bloqueos de grano, la Real Pragmática impedía el almacenamiento con fines de monopolio, tratos ilícitos y lucro. ${ }^{28}$

Otro aspecto que la Real Pragmática contemplaba era el de los precios, cuya regulación debería hacerse anualmente, quince días antes o después de la Virgen de Septiembre, dando también la oportunidad de extraer granos fuera del reino siempre que el precio no sobrepasara las tarifas estipuladas, pudiéndose almacenar a seis leguas como mínimo de donde se recibiese.

Evidentemente la Real Pragmática contenía unas prescripciones demasiado amplias, necesitando una reglamentación adicional que la hiciera viable. La respuesta a esta necesidad, no se hizo esperar: mediante la resolución de 29 de agosto y la Provisión Acordada del Consejo del 30 de octubre del mismo año 1765 se estableció un marco de garantías dentro del cual la Real Pragmática podría tener un desenvolvimiento práctico. No es extraño, pues, que estas garantías fueran frecuentemente el punto de mira para los Diputados del Común en su recién estrenado cargo, porque efectivamente se orientaban a asegurar el cumplimiento de la Real Pragmática. Para ello y en primer lugar se consideraba al Consejo como único órgano asesor en cuanto a las dudas que se generasen alrededor de su aplicación.

Toda la problemática de los acopios también tenía cabida dentro de estas dos leyes en cuanto a su vigilancia por parte de Intendentes, Corregidores y Ayuntamientos, así como la que surgiera alrededor del pan, asunto en plena fase de conflictividad durante estos años. Respecto a este producto final del trigo, su precio debería ir acorde con el costo y costes de los granos, y en los lugares donde no hubiera cosecha sufi-

26. Recordaba Esquilache que esta venta libre de granos se venía practicando ya en Inglaterra, Francia e Italia. Op. cit, p.4.

27. ANES, Gonzalo, Los Borbones, Alfaguara.Madrid 1975, p. 280.

28. Javier Guillamón incide en este punto observando que: «Las dificultades y peligros barruntadas inocentemente en sus propios capítulos para su cumplimiento, originaron que por la resolución de 29 de agosto y Provisión Acordada del Consejo de 30 de ocubre del mismo año se especificase mejor la anterior Pragmática». Javier GUILLAMON, Las reformas de la administración local durante el reinado de Carlos III, Madrid 1980, pp. 139, 40. 
ciente, caso de Alicante, el Ayuntamiento y el Síndico del Común deberían establecer el número de panaderos adecuado, bajo condición de amasar el grano aunque el trigo fuera de repuesto público. También se aconsejaba en las ciudades populosas el fomento de mercados públicos. Se trataba ante todo de prevenir crísis de subsistencias, ya que en casos de extrema necesidad estas leyes prescribían recurrir a los comerciantes de granos, entendiéndose como tales a los arrendadores de rentas «dominicales, decimales u otras que tomasen los granos sólo para hacer este comercion, es decir, se acotaba muy certeramente el terreno de la especulación, pero no se vacilaba en recurrir a ella en casos extremos.

Sin duda, hubiera sido muy pretencioso esperar la observancia de todos los capítulos que desplegaban ambas disposiciones; por eso en el mes de agosto de 1768 se hizo pública una nueva relación de ordenanzas. En ellas se mandaba a los comerciantes en granos que presentaran al corregidor sus respectivos libros para que fuesen rubricados por el escribano del Ayuntamiento sin cobrar derechos; éste debía además confeccionar una lista de los comerciantes matriculados para que, pasados 8 días desde la publicación de esta Provisión sin haber cumplido el asiento, se les decomisara sus granos. Se prohibía también en esta ley fijar precios a los granos para su compra bajo la pena de un mes de arresto y pago de las costas sin excepción, dándose cuenta de todo esto por parte de la Justicia del Concejo. Gonzalo Anes destaca la representatividad de la Pragmática, en medio de una política anárquica frente al abastecimiento, dándose la paradoja de la permanencia, junto a este intento liberalizador, de un sistema de licencia previa para cualquier traslado de trigo. ${ }^{29}$

\section{6: LOS CONFLICTOS DE MARZO Y LA INCORPORACIÓN DE LOS NUEVOS CARGOS: SÍNDICOS PERSONEROS Y DIPUTADOS DEL COMÚN}

Cuando Aranda abandonó Valencia con destino a la Presidencia del Consejo de Castilla, tras los sucesos de marzo de 1766, el mando militar del reino recayó interinamente en Jose Ladrón de Guevara, corregidor-gobernador de Alicante, por lo que la ciudad se convirtió en el centro coordinador de las operaciones militares, movimientos de tropas, etc., del antiguo Reino valenciano.

Simultáneamente a la aparición de pasquines en Valencia comenzó la agitación en Alicante, Orihuela y Cartagena. En Alicante ciudad no llegó a cuajar la explosión violenta como tampoco en los pueblos de su circunscripción ya que las autoridades locales se apresuraron a bajar los precios del pan, aceite y otros productos. ${ }^{30}$

En Alicante, los precios que hemos visto de 48 reales de vellón por fanega de trigo y 25 en la cebada para mayo de 1766 , contrastaban con los 41 y 14 respectivamente tan sólo en octubre de 1764. Una subida muy brusca si tenemos en cuenta que el trigo corría en abundancia por la ciudad con destino a Madrid. En estas circunstancias, es lógico que el descontento cundiera. Ladrón de Guevara debería sentirse preocupado por las proporciones que podría alcanzar un motín popular, pues recibía en la

29. Gonzalo ANES, Las crísis agrarias en la España moderna, Madrid, 1944, pp. 399-401

30. El gobernador José Ladrón de Guevara, intentó justificarse ante el secretario de Hacienda, Miguel de Múzquiz por haber decretado la baja de los precios, invocando las drásticas subidas que, en el trigo de importación había ordenado sucesivamente el marqués de Esquilache. José Miguel PALOP RAMOS, Op. cit., p. 151. 
primera decena de abril demandas de ayuda militar desde Valencia, Orihuela y Cartagena, situación que le obligó a rebajar el precio de la arroba de harina en 4 sueldos y 2 dineros -el pan debía guardar proporcionalmente esta baja- y 15 sueldos el cahíz de trigo. Ante las insuficientes existencias del pósito, el gobernador no titubeó en recurrir al grano importado por el gobierno y del que había almacenado en Alicante: más de 170.000 fanegas $^{31}$. Gracias a estas medidas aprobadas por el rey y a la garantía que suponía para Alicante poder disponer del trigo gubernamental, José Ladrón de Guevara quedó con las manos libres para poder actuar allí donde surgiesen las sucesivas perturbaciones, caso de Elche ${ }^{32}$, Albatera, Almoradí, etc., sin olvidar las inquietantes noticias que llegaban de Madrid.

La primavera sin embargo se presentó con tintes menos optimistas; la falta de harina en abril ${ }^{33}$ y más tarde la sequía en el mes de mayo que impedía moler el trigo hicieron que la situación se agravara ${ }^{34}$, originando una fuerte subida en los precios. ${ }^{35}$

Precisamente en este clima incierto, tuvo lugar en Alicante la integración de Diputados y Personeros del común, cuyas actuaciones iban a incidir directamente en el capítulo de abastos.

El anuncio de la llegada de estos nuevos agentes se hizo en cabildo de 17 de mayo y por medio de una carta, el corregidor, convaleciente de su larga enfermedad, dió la orden para convocar Ayuntamiento «...deseaba la ciudad instruirse del Auto Acordado del Consejo en que anula las bajas de comestibles hechas por asonadas o tumultos y manda elija el pueblo diputados que intervengan en el gobierno de sus abastos y un Procurador Síndico Personero, que siempre habian sido sus pensamientos tratar con la ciudad este asunto antes de su publicación, lo cual no corría tanta urgencia, ya que por no haber habido aquí bajas causadas por tales asonadas, ya también por no habérseme dirigido más que un ejemplar y ofreciéndoseme remitir los demás así como se fuesen imprimiendo no podía correr la publicata por los pueblos de la gobernación como es debido ${ }^{36}$. Como colofón se expresó la voluntad de tratar el tema entre corre-

31. I. Miguel PALOP RAMOS, El litoral valenciano y el avituallamiento triguero de Madrid. Hambres de 1754 y 1766. Estudis, número 5 (1976), pp. 125-155.

32. «La originalidad de esta revuelta ilicitana de 1766 es que nos muestra una compleja y variada problemática social que, aún conteniendo elementos tan diversos entre sí como la vieja petición de reversión o la más reciente lucha de los trabajadores por su subsistencia, va más allá de los típicos conflictos del feudalismo: revueltas campesinas, revueltas de los caballeros y ciudadanos contra la formación de un señorí y motines de subsistencia». Pedro RUIZ TORRES, Señores y Propietarios. Cambio social en el sur del País Valenciano: 1650-1850.

33. En cabildo de 26 de abril se comunicó que se había detectado falta de harina en la plaza cubriendo esta falta con la poca que quedaba en el pósito. A.M.A. Cabildos., Arm 9, Lib 56, acta capitular de 16 de mayo de 1766.

34. Se acordó que Alcaraz comprara 140 cahíces de trigo para enviarlos por mar a Altea, donde podrían molerse ...que el comín pueda estar asistido de ella (harina) y si en adelante se experimenta escasez contintie dicho diputado en nuevas remesas. A.M.A. Cabildos. Arm 9, Lib 56, acta capitular de 16 de mayo de 1766.

35. A raíz de la presentación de cuentas por el administrador se decidió aumentar la libra de pan a más de 8 dineros, disminuyendo onza y media. Por otra parte la arroba de harina pasaba a costar 17 sueldos y 8 dineros. Ibid.

36. A.M.A. Cabildos, Arm. 9, Lib. 57, acta capitular de 17 de mayo de 1766. La cantidad correspondiente a beneficio sería pues de 7601 libras, 2 sueldos, 8 dineros. 
gidor y diputados si estos estaban de acuerdo. Los términos de la carta indican que no había demasiada prisa por ir adoptando las medidas fijadas en el Auto Acordado.

Los nuevos cargos de Diputado y Personero del Común no tardaron en sumergirse en el ya crónico enfrentamiento entre los capitulares y el administrador, Vicente Ghessy. El motivo de esta primera confrontación fue la tardanza del administrador en presentar la cuenta anual. Cuando por fin lo hizo, los capitulares no la aceptaron; faltaban en ella las justificaciones de gastos y el libro de entradas y salidas. La carta que recibió el consistorio de parte del administrador decía que «...el requerimiento le ha causado -a Vicente Ghessy- angustia por la urgencia con que se le ha pedido la cuenta y que ha repercutido en su salud, y que, antes de poner la firma en la cuenta consiguió advertir el error de 914 libras 2 sueldos 8 dineros contra el pósito, cantidad que debe aumentarse al beneficio, considerándose por existentes en el caudal hasta último de junio de este año» ${ }^{37}$.

El cuerpo capitular se veía amenazado por distintos flancos y ahora tenía la oportunidad de ejercer su fuerza, mediante la presentación de objecciones a las cuentas presentadas por el administrador. Estas objecciones iban desde las puramente formales, hasta llegar a aquellas que afectaban directamente a la administración del pósito.

Según los capitulares, las cuentas presentadas por el administrador Vicente Ghessy se alejaban mucho de ser claras y pormenorizadas, muy al contrario presentaban una equivocación contra el pósito de 914 pesos, 2 sueldos y dos dineros, sin tener los diputados ninguna posibilidad de averiguar si el administrador había presentado la relación de compra de grano en los años anteriores, es decir, Vicente Ghessy no llevaba libros de compras y ventas de granos, o no los quería presentar ante el cabildo.

Otro grupo de irregularidades que el indignado cuerpo capitular detectaba se refería a la falta de datos en aquellas cuentas que de alguna manera se habían intentado presentar como correctas. Datos como la identidad de los sujetos a quienes se había vendido el trigo, motivos de variaciones de precios, cantidades de harina que las distintas medidas de trigo molido habían producido, y una serie de defectos de método y forma justificaban este rechazo en bloque por parte de los regidores..$^{38}$

En este contexto, es muy reveladora la carta que envió al cabildo el Secretario de Gracia y Justicia, D. Manuel de Roda, defendiendo veladamente la actuación del administrador y adelantándose a una posible usurpación de competencias por parte de los recién estrenados interventores, recordándoles hasta donde llegaban sus prerrogativas ${ }^{39}$. Sin este apoyo manifestado, casi prematuramente por parte de la administración central al administrador del pósito alicantino, no se comprende su largo ejercicio, presidido siempre por la desorganización y abocado por tanto a generar la sospecha de fraudes en las operaciones que dentro del pósito se venían tramitando.

37. A.M.A. Cabildos. Arm 9, lib 56, acta cap de 21 de julio de 1766.

38. Ibid.

39. «...no hallo inconveniente en que tales Diputados y Síndico puedan tomar conocimiento del estado de sus fondos (del pósito) para compras de granos en los tiempos oportunos, alzas y bajas de pan y representarme si advirtiesen malversación de ellos u otra cosa digna de remedio sin que su acción se extienda a más efecto por estar prescrito en la Novísima Instrucción el modo y forma con que han de manejarse los interventores en todos los casos. A.M.A. Cabildos. Arm. 9, lib. 57, Acta capitular de 28-71766. 
El conflicto en torno al descontento del cabildo por la falta de rigor de Ghessy a la hora de presentar sus cuentas es visto por María Dolores Rubio como un problema de preeminencias, que ilustra la continua resistencia de los municipios a la centralización ${ }^{\text {to }}$, pero de cualquier forma, y como hemos podido constatar, es ese poder central el que mantenía el hilo que amparaba arbitrariedades difíciles de combatir y que en definitiva suponían el principal escollo para imponer una linea continuista que avalara reformas firmemente sustentadas.

El inicio del año 1767 presentó la novedad del acuerdo de creación de un almodí público «para grano de todas especies con las reglas y métodos oportunos para su seguridad y facilidad» ${ }^{+1}$. Más adelante, en cabildo de 18 de noviembre de 1768 , el Ayuntamiento decidió que el administrador del pósito efectuara diariamente sus compras en este almacén público donde los trajineros depositaban los granos, después de que el público hubiese comprado, suspendiéndose de nuevo esta medida pocos días después. Esta inhibición del Ayuntamiento, y la muerte del almodinero antes de terminar el mismo mes de noviembre, marcaron un paréntesis en el funcionamiento del recién estrenado almodín, que reabrió sus puertas en 1769. El almodín se ubicó ahora en el almacén de José Ortuño, quien se avino a cumplir las normas que el Ayuntamiento le propuso. ${ }^{42}$

Las medidas gubernamentales acerca del acopio de granos no fueron, como vemos, especialmente seguidas y se apreciaba una tendencia a continuar con las antiguas prácticas. Los Diputados del Común, además de intervenir en el examen de las cuentas del pósito, en las compras de trigo y en las votaciones para decidir los acopios, eran comisionados por el Ayuntamiento para fijar el precio al que debía venderse la harina del pósito. En esta primera fase de actuación de los Diputados del Común se apreciaba, respecto a los regidores, una mayor sensibilidad en cuanto al posible riesgo que podía correr el abasto público en determinados momentos, postura que se traducía en una aceptación de las propuestas de acopio en los meses mayores y la inversa a partir del verano, para no forzar la subida de precios.

En el año 1768 afloraron un sinfín de contratiempos generados por un mismo hecho: el acopio de trigo en malas condiciones. La carestía de la harina y los altos precios unidos a la aparentemente beneficiosa propuesta del comerciante Mercadal propiciaron la compra en noviembre de 660 cahíces. Recién cerrado el trato y en el momento del descargo del trigo se advirtió su deficiente aspecto, pero se aceptó su almacenamiento en vista de que el patrón se hacía responsable del estado de la carga y se comprometía a una rebaja. Sin embargo un mes más tarde, en diciembre, el informe de los expertos no daba lugar a dudas:

40. María Dolores RUBIO FERNÁNDEZ, Elecciones en el Antiguo Régimen, p. 116.

41. El diputado Alcaraz propuso su ubicación en un almacén propiedad de Salvador Rodrigo; este sujeto percibiría 8 dineros por cada cahíz de grano, seis por almacén y almodinero y dos para un jornalero al servicio del almacén. A.M.A. Cabildos, Arm 9, lib 59, acta capitular de 16 de enero de 1767.

42. A.M.A. Cabildos, Arm. 9, Lib. 67, ff. 189-197 y 211-215. 
«El trigo de Mercadal tiene calor, mezcla de varias simientes como cebada y otras, suciedad y también gorgojo y gusanos que ahora empiezan a manifestarse» ${ }^{43}$.

A pesar de todo se siguió manteniendo el trigo en el pósito mientras que Mercadal proponía rebajarlo y limpiarlo a su costa. El apoyo firme del síndico Procurador General Ignacio Pérez de Sarrió en cuanto a sacar inmediatamente el trigo del pósito fue apoyado por el Síndico Personero y provocó unas confusas votaciones ante las cuales el Alcalde Mayor consideró como única solución efectuar la compra y cerrar el asunto. Cuando esta decisión y las razones por las que el Alcalde Mayor actuaba fueron presentadas al Concejo, las protestas capitulares se recrudecieron. ${ }^{44}$

Los posteriores testimonios de peritos, dando como válido el trigo, previo colado y garbillado, no convencieron como es lógico, a quienes estaban seguros de que las autoridades estaban actuando de espaldas al común y que vieron confirmada su sospecha cuando en una reunión totalmente clandestina, se cerró el trato abonando a Mercadal el coste del deteriorado trigo. Esta reunión se celebró en la posada donde se albergaba el corregidor y a ella asistieron el citado corregidor, quien entregó la llave para extraer el dinero del pago, además de cuatro regidores y el Síndico Personero. ${ }^{+5}$

Pero las verdaderas consecuencias de esta desafortunada adquisición se sufrieron en enero de 1769 , cuando se procedió al repartimiento forzoso de la harina del pósito procedente de este mismo trigo, provocando en el cabildo la protesta del Síndico Procurador General, que consideraba el acuerdo opuesto a las Ordenanzas del pósito, ya que no existía una necesidad pública de acopio en el momento de la orden. Ante la falta de apoyo por parte del Ayuntamiento, el Síndico acudió a Roda, quien en este caso apoyó la postura de Sarrió. A pesar de todo, el Ayuntamiento hizo caso omiso de la Orden, y una vez más se intentó zanjar el asunto al margen de las Ordenanzas. El conflicto resurgió en mayo cuando el Ayuntamiento ordenó la inhibición de harina forastera el 29 de dicho mes para obligar al común a consumir la harina del pósito. Después de una serie de enfrentamientos entre el bloque formado por el Síndico Personero y Diputados del Común unidos a las protestas populares, en cabildo de 6 de junio se decidió que el repartimiento comenzara aquella misma tarde, pero limitado a panaderos y amasadores, tras lo cual sería levantada la inhibición. ${ }^{46}$

El inicio de la década de los setenta que en conjunto, no presentó en nuestra ciudad la angustiosa escasez que se produjo en otras muchas de nuestra geografía sí acusó un momento de especial dificultad en 1770. El día 5 de mayo, el diputado Francisco Burgunyo anunció que el trigo que había en el pósito estaba totalmente agotado y que el único trigo existente en la ciudad era el del patrón Lorenzo Olivero, quien había vendido su cargo al comerciante Juan Bautista Morales. La acuciante necesidad de trigo que se detectaba en la ciudad queda plasmada en la comunicación de Burgunyo. Decía el regidor que el trigo del comerciante Juan Bautista Morales no había sido llevado al almacén porque se vendía en el propio mue-

43. A.M.A. Cabildos, Arm. 9, Lib. 61, Acta capitular de 3 de diciembre de 1768.

44. A.M.A. Cabildos, Arm. 9, Lib. 61, f. 178.

45. Ibid. p. 219

46. María Dolores Rubio Fernández: Elecciones en el Antiguo régiment.., pp. 129-130. 
lle «con gran aceleración $»^{47}$. Se acordó en consecuencia comprar 100 cahíces del que aún quedaba, para proveer el pósito. La falta de trigo por tanto no había quedado ni mucho menos resuelta y esta circunstancia impedía cerrar buenas operaciones de compra como volveremos a comprobar. Unos días más tarde llegó a la bahía alicantina, procedente de Marsella, el pingue «La María» transportando un cargo de 260 cahíces. El Ayuntamiento ofertó su total compra al precio de 13 libras el cahíz, pero fue el capitán del barco quien finalmente estipuló las condiciones de compra, que fijaban el precio del trigo en 13 libras menos 16 cuartos cada cahíz, a bordo de la embarcación, siendo de cuenta de la ciudad el coste del desembarco y conducción hasta el pósito. Además de estos requisitos, se pedía por parte del vendedor que la moneda mediante la cual se pagase el cargo, debía presentar una ley adecuada. ${ }^{+8}$

Un año después, en 1771 se volvió al temido recurso del repartimiento forzoso, pero por indicación del Intendente su puesta en funcionamiento se ciñó exclusivamente a las Ordenanzas de $1752 .{ }^{49}$ Este reparto hizo que los dos bloques enfrentados en cuanto a criterios de aprovisionamiento, se alejaran un poco más, pues mientras regidores y diputados recogían el clamor del común que estaba totalmente en contra de este procedimiento, el criterio de la superintendencia general, se inclinaba firmemente por el almacenamiento.

Las circunstancias hicieron que muy poco después el superintendente pudiera recriminar al cabildo su imprevisión, ya que la crísis 1771-72 se presentó con toda su crudeza, manteniéndose no obstante el cabildo en su idea primitiva de soslayar el acopio de granos, ya que aunque en febrero hubo necesidad de recurrir al proveedor de la tropa en busca de harina para amasar, la situación se resolvió en el mismo cabildo, el 7 de febrero de 1772, sin vacilaciones por parte del consistorio: «Que en los pueblos circunvecinos se compren hasta doscientos cahices de trigo a los precios más ventajosos que sea dable y se trasladen al pósito de esa ciudad reduciéndose a harina sirviendo para el abasto público según las urgencias que se reconozcan; en inteligencia de que dicha harina deberá venderse a costa y costes, sin comprehender los salarios de administrador y escribano a fin de que el precio no sea muy excesivo ni superior al de los trajineros ${ }^{50}$.

En el mes de marzo de 1773 y en vista de que sólo quedaban en el pósito alrededor de 80 cahíces, mientras el almodín carecía por completo de granos, se llegó a un acuerdo por parte del cuerpo capitular. Los diputados José Alcaraz y Jose Morell fueron los encargados de ajustar un trato con el comerciante Morales, que disponía de trigo en su sus almacenes, además de tener apalabrada la carga de la polacra «La Virgen del Rosario» y del bergantín «San Antonio de Padua», a un precio medio de 16 libras y media el cahíz. El comerciante se comprometía a vender trigo solamente al

47. A.M.A. Cabildos. Arm. 9, Lib. 64, acta capitular de 5 de mayo de 1770.

48. «en especie de oro que no sea defectuoso». A.M.A. Cabildos, Arm. 9, Lib. 63, f. 77.

49. ...Que hecha liquidación por el administrador del pósito de los precios de trigos y harinas de coste y costas, se firmen papeletas por el escribano de Ayuntamiento de la porción distribuida a cada vecino con expresión de ella al sujeto a quien se ha repartido y el precio del cahiz de trigo o arroba de harina A.M.A. Cabildos. Arm. 9, lib 64, fol 278

50. A.M.A.Cabildos. Arm. 9, Lib. 67, acta capitular de 7 febrero de 1772. 
común de la ciudad, mientras que el cabildo garantizaba el precio de venta del mismo, que quedaba en 16 libras y media el cahíz. Durante la sesión capitular de 7 de marzo de 1773 al intentar ilustrar acerca de lo ventajoso de esta operación, se hacía también un retrato muy esclarecedor sobre el momento que la ciudad atravesaba: «...Y oído por sus Señorías contemplando esta proposición por muy útil ventajosa y beneficiosa al común como realmente lo es y lo acredita el hallarse en esta ciudad muchos comisionados de diferentes poblaciones de este reino para comprar trigo para sus respectivos acopios, siendo tanta la escasez que de aquellas poblaciones que por sus abundantes cosechas han facilitado en estos años de sus sobrantes crecidísimas porciones para el abasto de estas ciudad, en el presente no sólo no pueden dispensar este beneficio si que por ser las más necesitadas han procurado extraer del que ha llegado a esta ciudad...». ${ }^{51}$

Poco después, el cabildo, ante la dificultad del momento pudo desplegar su capacidad negociadora, cuando la villa de Muchamiel acudió a la ciudad ante la escasez de trigo y cebada reclamando tres cahíces diarios de trigo para que no faltase pan en la villa. El consistorio respondió que estaba dispuesto a conceder «cahíz y medio diarios», pero no desaprovechó la ocasión de sacar partido a la concesión pidiendo simultáneamente que Muchamiel «señale dos molinos para la molienda de esta ciudad, con preferencia a otros -pueblos- cualesquiera». La carta que se recibió a continuación procedente de la villa propició un acuerdo ventajoso para las dos partes: «...deseando este Ayuntamiento la buena correspondencia con esa ciudad como siempre lo ha hecho, ha resuelto se le señalen por ahora, para la molienda de esa ciudad tres molinos...Por lo que de nuevo suplica tenga a bien concederle por lo menos hasta dos cahíces diarios $\aleph^{52}$. La propuesta fue aceptada por el cabildo sin ninguna otra condición. ${ }^{53}$

Los intentos de almacenar trigo de las comarcas vecinas en verano de 1773 fracasaron y pronto el precio del pan alcanzó niveles que se consideraron preocupantes. La situación se agravaba por la falta de previsión de los comerciantes, y por la escasez en los mercados exportadores habituales, hasta que la llegada de embarcaciones con trigo en 1774 y la posterior baja operada en el precio volvió a plantear el conflictivo tema del reparto, ya que aun quedaba bastante trigo en el pósito. Por fin se decidió dar salida a los 104 cahíces almacenados al precio corriente aunque el pósito sufriera una pérdida. Esta era la única manera de evitar tumultos, como ya se había podido comprobar anteriormente. ${ }^{5 \downarrow}$

En mayo de 1775, fue preciso comprar a la viuda de Juan Bautista Fabián 367 cahíces, 11 barchillas y 1/2 de trigo para el pósito al precio de 14 libras el cahíz, porque volvía a percibirse la escasez de cada primavera, tanto de trigo como de harina. A estas dificultades se unió este año otra adicional. El 12 de junio se recibió en cabildo la queja de que casi todos los molinos estaban ocupados moliendo trigo de

51. A.M.A. Cabildos, Arm. 9, Lib. 68, acta capitular de 3 de marzo de 1773.

52. A.M.A. Cabildos, Arm. 9, Lib. 68, ff. 191-92.

53. Ibíd.

54. A.M.A. Cartas escritas. Arm. 12, Lib. 61, s.f., carta al Superintendente general de pósitos de 30 de abril de 1774 . 
S.M. Inmediatamente se acordó una entrevista con el Comisario de Guerra, pues la ciudad corría peligro de quedarse sin harinas si no quedaban libres los molinos necesarios. ${ }^{55}$

A partir de 1775 entramos en lo que supone ya la definitiva y lenta agonía de este organismo que iba quedando obsoleto ante las nuevas corrientes económicas y comerciales. La contestación que el cabildo hizo a la carta del Superintendente General de Positos, D. Manuel de Roda el día 11 de noviembre de 1775 nos da una referencia acerca de lo que va a ser una nueva etapa en el funcionamiento de los pósitos: «...Se recibe orden de D. Manuel de Roda, superintendente general de pósitos, conteniendo reglas generales para el gobierno y administración de los pósitos. Como esta ciudad se rige por ordenanza particular con la que son incompatibles muchas de dichas reglas; se acuerda: Pasar orden a los Sres. Burgunyo, Caturla y Torregrosa para que informen lo que crean».56

Por otra parte, la casa Asegurada, edificio destinado para almacén del pósito, sirvió durante unos meses de 1778 como refugio para la tropa otra circunstancia que refleja la escasa actividad que el pósito venía desarrollando ${ }^{57}$ Cuando, aún en este mismo año de nuevo se recibió una orden del Superintendente en el sentido de que la ciudad hiciese acopio de granos ya que había dificultades en el tráfico marítimo por la guerra franco-inglesa y se temía que España entrase en el conflicto, la decisión que tomó el cabildo de acopiar grano fue protestada por el Diputado del Común, Juan $\mathrm{Fe}$ rrando y Martras, en dos ocasiones, triunfando definitivamente el criterio de no hacer acopio de grano y regirse por la necesidad del momento..$^{58}$

La decisión de España en 1779 en el sentido de prestar ayuda a los insurgentes de las Trece Colonias, y el consiguiente enfrentamiento con Inglaterra acentuaron las dificultades del tráfico marítimo obstaculizando la compra de productos agrícolas y manufacturados procedentes de Europa. En toda la región valenciana cayó de manera violenta el comercio hasta 1783. Esta situación de crisis generalizada hizo que la especulación por parte de panaderos y horneros se extendiera de una forma incontrolable. La única respuesta de las autoridades locales, que buscaban en algunas ocasiones el respaldo del Consejo de Castilla, fue volver a las prácticas paternalistas de protección al consumidor. La escalada de los precios y la escasez dimanante del acaparamiento exigían en aquella coyuntura el abandono del nuevo «espíritu del 65», para volver a las prácticas tradicionales protegiendo el consumo. ${ }^{59}$

El cabildo alicantino inmerso en esta dinámica, se apresuró a comprar trigo para el pósito siempre que creía ver en peligro la subsistencia diaria de las clases más castigadas, pero cada vez que esto ocurría, se desvelaba la especulación por parte de los

55. A.M.A. Cabildos, Arm. 9, Lib. 70, acta capitular de 16 de junio de 1775.

56. A.M.A. Cabildos, Arm. 9, Lib. 70, f. 302.

57. ...como el acopio no puede ejecutarse sin casa en la que depositar los granos y la Asegurada que sirve de pósito se halle ocupada aín por la tropa, por disposición de S.Ex.se le repita oficio(al comisario de Guerra) a fin de que providencie su pronta evacuación en el estado en que la ciudad la entregó. A.M.A. Cabildos. Arm. 9, Lib. 73, acta capitular de 25 de octubre de 1778.

58. A.M.A. Cabildos. Arm. 9, Lib. 73, acta cap. de 25 de octubre de 1778.

59. J. Miguel Palop Ramos, «Hambre y lucha antifeudal». Las crisis de subsistencias en Valencia (s. XVIII). pag. 198. 
panaderos que sí disponían de harina, pero no tenían ningún interés por bajar precios en la venta de pan.

En octubre de 1780 , debido al aumento de precio del trigo, se estableció en ocho dineros el precio del pan de diez onzas. ${ }^{60} \mathrm{El} 31$ de diciembre de este mismo año, en vista de la existencia en el pósito de seiscientos sesenta y cuatro cahíces de trigo a los que no se veía manera de dar salida, se decretó la inhibición general de trigos y harinas hasta que este trigo no fuese consumido en su totalidad. Los once panaderos de ciudad (D. López, V. LLacer, A. García, J. Martellet, B. Abilla, F. Sánchez, J. Alcaraz y L. Viñas, Fco. Selfa, V. Selfa y J. Navarro) se obligaron a consumir cada día treinta cahíces del referido trigo, prohibiéndose hacer pan a cualquier otro amasador particular bajo la pena de tres libras y comiso de la harina. ${ }^{61}$

En cabildo de 15 de enero de 1781 se expuso la necesidad de tomar medidas para despachar el trigo que había en el pósito. Ante la dificultad que entrañaba esta operación, de la que todos los capitulares eran conscientes, Pascual de Pobil responsable del último acopio se vio en las necesidad de justificar las razones que le obligaron a comprar un trigo que ahora no tenía salida. La carencia total de trigo en la ciudad durante dos días abocó al comisionado a comprarlo en Cartagena. Los inconvenientes de esta precipitada compra los explicaba el propio Pobil:

"...obligándosele a pagar su importe luego que se le entregase medido sobre el muelle de este puerto y que la detención por el embargo hecho de dicho trigo por el gobernador de Cartagena y malos tiempos retardaron su arribo por muchos dias; causa de calentarse algo y que puesto en la Asegurada fermentase algún gorgojo... ${ }^{12}$

El fracaso total de este acopio se acentuó poco más tarde, explicaba Pobil, al llegar por mar unos cargos que aliviaron la situación quedándose otra vez estancado el acopio del pósito ya que, según continuaba narrando Pobil:

«En vista de que ningunas (medidas) bastan para remediar los fraudes como lo acredita la experiencia, pues desde dicho día hasta el presente sólo se han extraido del pósito noventa cahíces, quando el cálculo regular de este pueblo es de cincuenta diarios de consumo que deberían ser trescientos; añadiéndose a éste el que de cada día pierde de su bondad el trigo y es el pobre el único que sufre todos los perjuicios. Se hace evidente la necesidad de que el Ayuntamiento estreche sus providencias para evitar tantos daños ${ }^{63}$.

El día 18 de enero existían todavía en el pósito 460 cahíces de trigo, por lo que se insistió en la inhibición del trigo y, ante la persistente oposición de los panaderos a acatar la voluntad del Ayuntamiento, éste reaccionó endureciendo las medidas represivas, ya que se exigía del panadero la papeleta firmada por el administrador acreditando que el trigo procedía del pósito, bajo la pena de comiso y veinticinco pesos de multa; se prohibía la introducción de pan cocido bajo pena de comiso y se impedía a todos los amasadores cocer pan que no fuera de la harina del pósito, bajo multa de tres libras y de comiso. Por último, se comisionaba al regidor Juan Pobil y al diputado del Común Domingo Moro para que hicieran inventario del trigo y harina que

60. A.M.A. Cabildos, Arm. 9, Lib. 75. Acta capitular de 11 de octubre de 1780.

61. A.M.A. Cabildos, Arm. 9, Lib. 75. Acta capitular de 31 de diciembre de 1780.

62. A.M.A. Cabildos, Arm. 9, Lib. 76. Acta capitular de 15 de enero de 1781.

63. A.M.A. Cabildos, Arm. 9, Lib. 76. Acta capitular de 15 de enero de 1781. 
quedara en poder de los panaderos. Como, sin duda, éstos tenían en su poder otras harinas, los agentes municipales nombrados para el caso, se hacían depositarios de ellas hasta que los panaderos utilizaran la harina del pósito, bajo una multa de cien libras. ${ }^{6 t}$

La especulación en este asunto fue latente, por lo que se impuso un replanteo de la situación. En marzo el Síndico Personero hizo una relación individual del número de cahices de trigo fuerte, blando y candeal que en el día 7 de este mismo mes había en la ciudad, su precio, peso y dueños del mismo, resultando haber tres mil setenta cahíces. ${ }^{.5}$ De todo este complicado proceso aclaratorio se logró por fin extraer una medida que permitiera dar un respiro al común más necesitado: el aumento de una onza de pan en masa por cada rollo de ocho dineros. ${ }^{66}$

Esta bonanza no tardó en enturbiarse, y en julio, los panaderos de la ciudad enviaron un escrito al cabildo quejándose de que las harinas habían subido de precio llegando a 19 sueldos y cuatro dineros y aún a 19 sueldos y medio cada arroba, y no podían dar el peso de diez y seis onzas y media en cada rollo de pan por el precio de ocho dineros. Solicitaban por tanto una calicata u otro sistema que estipulase el precio del pan de acuerdo con el precio real de las harinas. ${ }^{67}$

Los años 1782 y 1783 están marcados por las continuas quejas de los panaderos, exponiendo sus teorías de pérdida de dinero por la política seguida de aumento en el peso del pan, mientras que los capitulares objetaban la bajada ocasional del precio de los granos y las mezclas de harinas que los panaderos seguían practicando. En cabildo de 14 de marzo de 1784, y por fallecimiento de Vicente Ghessy, fue elegido un nuevo administrador del pósito, D. Juan Sese.$^{68}$ El nuevo administrador no tenía asignado un salario fijo, sino que recibiría sus emolumentos en función del trigo acopiado.

La escasez de granos volvió a sentirse con fuerza en Alicante en 1785. La relación de trigo que quedaba en los almacenes de la ciudad el día 19 de abril, y que fue facilitada al cabildo por los fieles ejecutores, no daba lugar a duda:

En el almodín

Trigo sexa: 140 cahíces a 14 libras, 4 dineros

trigo candeal: 30 cahíces a 14 libras, 14 dineros

trigo fuerte: 11 cahíces a 16 libras, 16 dineros

En los almacenes de Fabián y Bautista Morales:

Trigo fuerte y sexa sobre 30 cahíces a 17 libras el fuerte y sexa a 14.

Como ya había ocurrido en situaciones similares, el cabildo previno males mayores ordenando que de los almacenes de Fabián y Morales no se vendiera ningún trigo a quien no llevara una papeleta acreditada por los fieles ejecutores. ${ }^{69}$

La situación llegó a ser tan alarmante en noviembre de 1785 que el cuerpo capitular en pleno decidió pedir al Secretario de Hacienda, D. Pedro de Lerena que se su-

64. A.M.A. Cabildos, Arm. 9, Lib. 76, p. 24,25.

65. A.M.A. Cabildos, Arm. 9, Lib. 76. Acta capitular de 9 de marzo de 1781.

66. A.M.A. Cabildos. Arm. 9, Lib. 76. Acta capitular de 27 de mayo.

67. A.M.A. Cabildos. Arm. 9, Lib. 76. Acta capitular de 17 de junio de 1781.

68. Este nuevo administrador del pósito dejó de prestar sus servicios al frente del mismo, en diciembre de 1785, cuando fue nombrado Guarda-Almacén del Real Consulado de Alicante.A.M.A. Cabildos, Arm.

9, Lib. 80, acta capitular de 2 de diciembre de 1785 .

69. A.M.A. Cabildos, Arm. 9, Lib. 79. Acta capitular de 19 de abril de 1785. 
primiese el derecho Real de Aduana, que se imponía al ingreso de los trigos extranjeros «...por lo menos durante la actual necesidad»."

Quizá sea éste el primer momento en que se detectaba la dificultad del municipio para poder asegurar el grano necesario diariamente; se recurrió en agosto ante el Consejo ", asumiendo el papel proteccionista para saber si era lícito que en situación de gran escasez se pudiera extraer granos de la provincia con destino a otras provincias. ${ }^{72}$ Pero ya no se confiaba en el acopio masivo de grano como medio para prevenir escaseces.

La que podríamos llamar última fase del pósito alicantino se inició con la decisión de que el edificio de la Asegurada que había sido su lugar de ubicación, fuese también el que albergara el almodín; la exigua actividad del pósito hacía que este cambio supusiera la posibilidad de contar con unos ingresos adicionales por parte de la ciudad. El almodinero, Vicente Llacer, también estaba dispuesto a asumir el cargo de administrador del pósito. El nuevo almodinero-administrador se avenía a pagar 40 libras anuales ${ }^{73}$ en concepto de alquiler. En su trabajo de administrador, Lácer no tendría derecho a ningún salario fijo, y el que recibiera sería proporcionado a los acopio que hiciera el pósito, si es que hubiera alguno. ${ }^{74}$

Las nuevas ordenanzas por las que se regía el almodín fueron elaboradas por el regidor D. Bernardo Torregrosa y el Diputado del Común D. Juan de Güemes y, por medio de ellas, se prescribían las obligaciones del almodinero en cuanto a recibir y colocar en el zaguán o primer piso de la Casa de la Asegurada todos los granos que se condujeran a Alicante para venderse, quedando responsable de entregar al dueño cuando éste lo precisara, bien la cantidad que se depositó inicialmente, o su justo valor (en moneda o especie estipulada). La cantidad que el almodinero debía recibir de los dueños del trigo, por el trabajo de custodiar el grano y hacer las operaciones pertinentes de entregas, pagos, etc., tendría que ser de un sueldo por cahíz en el momento de la entrega y, pasado un mes desde que el trigo se había puesto en el almodín, un sueldo por cahíz cada mes.

En cuanto a las obligaciones que el almodinero debía cumplir estaban la de tener abierta dicha casa de la Asegurada: en el invierno desde las ocho hasta las doce de la mañana y desde las dos hasta las cinco de la tarde; en el verano desde las seis hasta las doce y desde las tres hasta las siete. Otra obligación del almodinero era la de hacerse cargo de la citada casa de la Asegurada responsabilizándose del cuidado de los

70. A.M.A. Cabildos, Arm. 9, lib. 80. Acta Cap. de 2 nov. de 1785.

71. Esta consulta se hizo a raíz de la venta de 50 cahíces de trigo con destino a Cádiz ajustada por el comerciante local Pedro la Viña. A.M.A. Cabildos, Arm. 9, Lib. 80. Acta capitular de 2 de octubre de 1785.

72. Un año más tarde, en septiembre de 1786 , se recibió la concesión de este privilegio, «...concediéndose absoluta libertad de derechos de rentas generales a todo el trigo, cebada y maiz que se introduzca ya sea en trigo o harina, por cualquier puerto de estos dominio hasta final de agosto de 1787, con motivo de la escasa cosecha que se ha experimentado en el reino". A.M.A. Cabildos, Arm. 9, Lib. 80. Acta capitular de 4 de septiembre de 1776.

73. Al inicio de las negociaciones, Lacear oferta sólo 20 libras. A.M.A. Cabildos, Arm. 9, Lib. 81. Acta capitular de 23 de julio de 1886 .

74. Ibíd. 
utensilios que había en ella, debiendo satisfacer anualmente para la conservación del edificio cuarenta pesos de alquiler al Ayuntamiento. ${ }^{75}$

Por último, quedaba prescrito en las ordenanzas que el régimen y gobierno del pósito dependieran de la Justicia y el Ayuntamiento de la ciudad, debiendo el almodinero observar y cumplir las órdenes que éste y sus fieles ejecutores le diesen como fiel administrador del pósito.

Las sesiones capitulares de los años 1788 y 1789 , tocantes a cuestiones relacionadas con el abasto del trigo se centraban ya sobre todo en la problemática del pan, tanto en cuanto a su cantidad, como a calidad y precio. Las escaseces castellanas por las continuadas sequías mantuvieron presente la desgravación arancelaria hasta 1794 y sólo las medidas tomadas por los magistrados alicantinos ayudaron a paliar la crísis de 1789.

\section{CONCLUSIONES}

Cabe apuntar finalmente que, en una ciudad como Alicante, abierta al grano mediterráneo y punto de reparto para una importante cantidad del reclamado por la Corte, un pósito, diseñado bajo criterios afines a las características de las localidades castellanas, tenía pocas probabilidades de conseguir los objetivos previstos tras su creación, circunstancia que no se escapó a las observaciones de figuras autorizadas que veían en él un reducto proclive a todo tipo de malversaciones y fraudes. Las características climatológicas de la plaza alicantina, con el fuerte calor y humedad muy poco beneficiosos para el almacenamiento de grano, tambien eran mencionadas cada vez que se ofrecían argumentos en contra de los depósitos de trigo, mientras que otras muchas descripciones emitidas en las sesiones capitulares nos muestran, por contra, la ventajosa situación real de la ciudad, respecto de la gran mayoría de ciudades españolas.

Lo cierto es que, a pesar de reunir muchos condicionantes favorables frente al problema concerniente al abasto de trigo, no estuvo la ciudad a salvo de carestías y sobresaltos debido en un gran número de ocasiones, no a una escasez real de grano, sino sobre todo a la deficiente gestión de los agentes implicados en tan fundamental proceso: un administrador del pósito que gozaba de excesiva autonomía dimanante sobre todo de la falta de coordinación en las relaciones corregidor-regidores, situación que el administrador del pósito capitalizaba a su favor, llevando a cabo operaciones que distaban de ser acertadas, y mucho menos transparentes y un corregidor habitualmente en conflicto con los capitulares.

Son muchos los indicios que nos hacen pensar, además, en una cierta inercia por parte de los encargados del pósito, que amparados en su función de prevenir posibles carestías se veían justificados ante operaciones precipitadas en la mayor parte de los casos, con la velada connivencia de un pequeño grupo capitular más proclive a las actitudes oligarcas. Muchas de estas operaciones de compra, de nefastas consecuencias, fueron denunciadas con energía en el cabildo alicantino, a partir de la implantación de los Diputados del Común; fueron ellos quienes evidenciaron la irregular administración del pósito, y reclamaron claridad en las cuentas del mismo, pero la ineficacia del pósito tenía otras muchas razones para el fracaso. 
Se evidencia también a través de las actas municipales que el consistorio en ningún momento, ni aún los más acuciantes, creía seriamente en una escasez larga o desesperaba, mientras que las alarmante noticias circulantes en determinados momentos eran el pretexto que amparaba de alguna manera muchas compras de grano, que muy pronto se revelaban inútiles y desequilibradoras de los precios, que conducían al pósito alicantino hacia su total inutilidad.

Nos parece, en definitiva oportuno reseñar aquí la afirmación de Enrique Giménez y Mario Martínez en cuanto a que los casos de los pósitos de Alicante y Oliva son probablemente paradigmáticos de la voluntad creadora de los pósitos por corregidores celosos de aplicar mecánicamente las órdenes recibidas de la superintendencia sin tener en cuenta las peculiaridades de la zona. ${ }^{76} \mathrm{~A}$ pesar de que según Anes las reservas de los pósitos en granos y en dinero se incrementaron notablemente desde 1733 a $1793^{77}$, y Jose Miguel Palop en la misma línea considera que su cenit coincide con los años 1791-92 ${ }^{78}$, en Alicante no se cumplió esta regla como hemos podido constatar, muy al contrario durante la etapa 1775-1788 el pósito alicantino como organismo que en algún momento fué efectivo, aún considerado como una imposición, poco a poco va teniendo un sentido que oscila desde ser un recurso de emergencia hasta asumir un papel casi testimonial.

No deja de ser además, un tanto significativo que, el afianzamiento de los Diputados del Común en la gestión de los asuntos referentes a abastos, materializado en la elaboración de las normas del almodín por el Diputado Juan de Güemes en 1785, llegara cuando este almacén creado como una réplica debilitada del fracasado pósito, no presentaba las mínimas condiciones materiales para desempeñar su función. ${ }^{79}$

La impresión del pósito como un proyecto ahogado ya desde su inicio se acentúa si junto a la anterior consideración evocamos el momento en que el corregidor, marqués de Alós, en su condición de representante y portavoz regio elaboraba las normas que iban a regir su funcionamiento. Su aislamiento total del cuerpo capitular, tanto desde el punto de vista personal como corporativo, abocaban al máximo representante municipal hacia una alianza más o menos tácita con un administrador que necesitaba este apoyo como medio para reforzar la legalidad de su gestión respecto al abastecimiento frumentario.

76. «De hecho, la mayor parte de los pósitos de nueva planta surgidos con posterioridad a 1751 (un $54,7 \%$ ) Io habían sido en territorio de la antigua corona de Aragón... pero Cataluña y Valencia no poseían tradición en este tipo de instituciones, tanto por su déficit cerealístico como por utilizar tradicionalemente el mecanismo de la importación de grano ultramarino» Enrique GIMÉNEZ LÓPEZ y Mario MARTÍNEZ GOMIS, La revitalización de los pósitos a mediados del S. XVIII, Política y Hacienda en el Antiguo Régimen, Murcia 1993, p. 287.

77. ANES, Gonzalo: «Los pósitos en la España del s. XVIII», en Economía e Ilustración, Ariel. Barcelona, 1969

78. PALOP RAMOS, José Miguel: «Fluctuaciones de precios y abastecimiento en la Valencia del S. XVIII», Instituto valenciano de Estudios Históricos, Institución Alfonso el Magnánimo.Valencia, 1977, p. 164.

79. Un memorial de Vicente LLácer exponía que: «...el suelo del descubierto de la casa Asegurada que sirve de almodin se halla más elevado que el piso del zaguán donde están los granos y que en el referido descubierto existen aún el banco y bovedillas que se dispusieron para la cocina cuando la tropa cocupaba dicha casa, hallándose desplomando éstas en términos que fácilmente podrán introducirse las aguas pluviales en el mencionado zaguán. con notable prejuicio de los granos». A.M.A. Cabildos, Arm.9, Lib. 81, acta capitular de 1 de septiembre de 1786. 